\title{
Modernization of Todini Global Gradient Algorithm for hydraulic analysis of networks with choked flow
}

\author{
Leonid Korelstein ${ }^{1 *}$ \\ ${ }^{1}$ Piping System Research \& Engineering Co (PSRE Co), Moscow, Russia
}

\begin{abstract}
The modification of well-known Global Gradient Algorithm for hydraulic network flow distribution problem is proposed. This modification is based on problem equations rewritten in "upstream" form and on modified form of linearization, and can be effectively used for piping networks with gas and multiphase gas-liquid flow with multiple choked flow.
\end{abstract}

\section{Introduction}

Different methods of solving hydraulic network flow distribution problem were proposed [1, 2], and Global Gradient Algorithm (GGA) was one of the most effective. GGA was proposed in [3-6] for liquid steady state flow, and was later extended for gas networks, networks with control valves [7, 8], and some types of non-steady state flow problems [9-11]. Application of GGA for process piping was investigated by the author and his colleagues in a number of publications [12-14], and PASS/HYDROSYTEM software [15], developed by PSRE Co, uses GGA successfully for thermal and hydraulic analysis of piping networks transporting both one-phase (liquid, gas) and multiphase phase gas-liquid fluids.

However, in its original form GGA cannot be applied to networks with choked or nearchoked flow - while analysis of such flow is an important practical problem for some types of process piping - for example pressure relieve discharge systems or multiphase gas-liquid transfer pipelines transporting oil from furnace to column. Such flow was investigated by the author in [16-19]. He also established conditions for existence and uniqueness of flow distribution problem solution for this type of flow [19].

This article proposes modified form of GGA (MGGA), which (along with decomposition method) hopefully allows to solve flow distribution problem for choked flows. Further in this article we will consider on hydraulic analysis, i.e. will consider $2^{\text {nd }}$ thermodynamic parameter (besides pressure) describing state of the fluid (for example temperature for isothermal flow or full enthalpy for adiabatic flow) to be fixed.

\section{GGA equations}

Let's remind equations of GGA in its classical form.

Classical hydraulic network flow distribution problem can be written as $[1,2]$

\footnotetext{
${ }^{*}$ Leonid Korelstein: Korelstein@truboprovod.ru
} 


$$
\begin{gathered}
A^{T} P=F(X) \\
A X=Q
\end{gathered}
$$

Where $A$ - incidence matrix of network graph, $X$ - vector of mass flow rates, $Q$ - node mass inflow vector, $P$ - vector of node potentials (pressures), $F(X)$ - vector function, each element of which is function of losses on edges.

It is supposed that node pressures are set in part of nodes (at least one), and inflow are defined in remaining nodes. We can rewrite matrices and vectors in (1), (2) as

$$
A=\left(\begin{array}{l}
A_{1} \\
A_{0}
\end{array}\right), P=\left(\begin{array}{l}
P_{1} \\
P_{0}
\end{array}\right), Q=\left(\begin{array}{l}
Q_{1} \\
Q_{0}
\end{array}\right)
$$

Where index 0 corresponds to nodes with set potentials, and index 1 -nodes with defined inflows. From (1), (2)

$$
\begin{gathered}
A_{1}^{T} P_{1}=F(X)-A_{0}^{T} P_{0} \\
A_{1} X=Q_{1}
\end{gathered}
$$

GGA searches solution of non-linear system of equations (4), (5) via $X$ and $P_{1}$, without any a-priory restrictions on vectors $X$ and $P$ in system (1) (this is the reason of the name "global"). On each iteration system (4), (5) is replaces by its linearization in the vicinity of current iteration, and linearized system is solved. Taking into account that

$$
F(X+\Delta X) \approx F(X)+D(X) \Delta X, \text { where } D(X)=\operatorname{diag}\left(\partial f_{j} / \partial x_{j}\right)
$$

From (4),(5) and (6) GGA equations can be reduced

$$
\begin{gathered}
P_{1}^{(i+1)}=P_{1}^{(i)}+M\left(X^{(i)}\right)^{-1}\left\{Q_{1}-A_{1} X^{(i)}-A_{1} D\left(X^{(i)}\right)^{-1}\left[A^{T} P^{(i)}-F\left(X^{(i)}\right)\right]\right\} \\
X^{(i+1)}=X^{(i)}+D\left(X^{(i)}\right)^{-1}\left[A^{T} P^{(i+1)}-F\left(X^{(i)}\right)\right]
\end{gathered}
$$

Where

$$
M(X)=A_{1} D(X)^{-1} A_{1}^{T}
$$

is Maxwell matrix - symmetrical positive-definite sparse diagonally dominant M-matrix [2024], which inversion in (7) can be done computationally effective.

GGA has some significant advantages: it converges very quickly, does not demand any preliminary topological analysis of the network, and also almost not sensitive to initial approximation quality.

However, in real process piping function $F(X)$ can depends not only on flow rate, but also on node pressure values [16-19]. While this dependence is weak $(|\partial F / \partial \ln P| \ll$ $|\partial F / \partial \ln X|)$, GGA works effectively. The more solution is close to choked flow, the worse is GGA convergency. And the worst difficulty is that iterations more and more often fall in the region where functions of losses on edges are not defined - some edges simply cannot transport current iteration flow rate value, as this value exceeds critical flow at current pressure in start edge node.

\section{MGGA equations}

To work around this problem, let's reformulate hydraulic network equations, switching from "downstream" calculation to "upstream" calculation:

$$
\begin{gathered}
A_{1}^{T} P_{1}=F^{*}(X, P)-A_{0}^{T} P_{0} \\
A_{1} X=Q_{1}
\end{gathered}
$$

Where losses function edge $\mathrm{j}$ is defined as function of flow rate and pressure in edge end node: $f_{j}^{*}\left(x_{j}, P_{\text {end }}\right)=P_{\text {beg }}\left(x_{j}, P_{\text {end }}\right)-P_{\text {end }}$. Upstream edge calculation (for set flow rate and end pressure) can be more difficult to do, but in this case the solution (except some exotic cases - for example edge with big height difference with downflow gas-liquid flow) always exists and is smooth.

Function $F^{*}(X, P)$ linearization can be written as 


$$
F^{*}(X+\Delta X, P+\Delta P) \approx F^{*}(X, P)+D(X, P) \Delta X+C(X, P)\left(A^{-}\right)^{T} \Delta P
$$

Where $A^{-}$- incidence matrix, containing only -1 value for incoming edges, and diagonal matrices $C(X, P)$ and $D(X, P)$ are defined as

$$
c_{i i}=1-\partial P_{\text {beg }}\left(x_{j}, P_{\text {end }}\right) / \partial P_{\text {end }}, d_{i i}=\partial P_{\text {beg }}\left(x_{j}, P_{\text {end }}\right) / \partial x_{j}
$$

Note that $0 \leq c_{i i} \leq 1$ and have clear physical sense - these values show how close is the flow on edges to choked one (value 1 corresponds to choked flow, 0 means that losses are independent of pressure value and depends only on pressure difference).

Substituting (12) into (10), (11), we get the following MGGA equations

$$
\begin{aligned}
& \quad P_{1}^{(i+1)}=P_{1}^{(i)}+M^{*}\left(X^{(i)}, P^{(i)}\right)^{-1}\left\{Q_{1}-A_{1} X^{(i)}-A_{1} D\left(X^{(i)}, P^{(i)}\right)^{-1}\left[A^{T} P^{(i)}-\right.\right. \\
& \left.\left.F^{*}\left(X^{(i)}, P^{(i)}\right)\right]\right\} \\
& \quad X^{(i+1)}=X^{(i)}+D\left(X^{(i)}, P^{(i)}\right)^{-1}\left[A^{T} P^{(i+1)}-F^{*}\left(X^{(i)}, P^{(i)}\right)-\right. \\
& \left.C\left(X^{(i)}, P^{(i)}\right) A_{1}^{-T} d P_{1}^{(i)}\right]
\end{aligned}
$$

Where

$$
\begin{aligned}
& d P_{1}^{(i)}=M^{*}\left(X^{(i)}, P^{(i)}\right)^{-1}\left\{Q_{1}-A_{1} X^{(i)}-A_{1} D\left(X^{(i)}, P^{(i)}\right)^{-1}\left[A^{T} P^{(i)}-\right.\right. \\
& \left.\left.F^{*}\left(X^{(i)}, P^{(i)}\right)\right]\right\}
\end{aligned}
$$

And generalized Maxwell matrix

$$
M^{*}(X, P)=A_{1} D(X, P)^{-1}\left[A_{1}^{T}-C(X, P) A_{1}^{-T}\right]
$$

Matrix $M^{*}$ is not symmetrical, but (in cases, when solution is unique- see [19]) still is sparse nonsingular WCDD M-matrix and can be inversed using effective calculation methods.

To preliminary check proposed MGGA, a series of calculation experiments was performed in cooperation with D.D. Fedyunina on small hydraulic networks. Isothermic ideal gas choked flow was modeled (in this case function $F^{*}$ and its derivatives can be calculated analytically). The results of experiments demonstrated that proposed method is working and keeps all its advantages - quick convergency and weak dependency on initial point. Moreover, with pressure as node potentials - not squares of pressures (which usually are used for gas networks) the convergence is even better. This can be explained by the fact that in case of choked flow, edge flow rate is proportional to start node pressure.

Currently the work is performing on implementation of general case of "upstream" calculation (with possible multiple choked flow and complete fluid vaporization or condensation) in PASS/HYSROSYSTEM program. In the same time additional computational experiments for adiabatic gas flow (Fanno flow) are scheduled, and on the base of their results MGGA implementation in PASS/HYDROSYSTEM is scheduled.

\section{References}

1. A.P. Merenkov, V.Y. Hasilev. Theory of Hydraulic Circuits (1985) [in Russian]

2. M.G. Suharev. Piping Systems of Energetics: Control of development and operation, 15 (Novosibirsk, Nauka, 2004) [in Russian]

3. E. Todini. Bollettino degli Ingegneri della Toscana, 11 (1979)

4. E. Todini, S. Pilati. In B. Coulbeck and C.H. Orr (eds). Computer Applications in Water Supply, 1 (System analysis and simulation), 1 (London: John Wiley \& Sons, 1988)

5. R. Salgado, E. Todini, P.E. O'Connell. In B. Coulbeck and C.H. Orr (eds) Computer Applications in Water Supply, 1 (System analysis and simulation), 38 (London: John Wiley \& Sons, 1988)

6. E. Todini. In R. Powell and K.S.Hindi (eds) Computing and Control for the Water Industry, 63 (Baldock, UK: Research Studies Press Ltd, 1999) 
7. R. Salgado, E. Todini, P.E. O' Connell. International Symposium on Computer Modelling of Water Distribution Systems (Lexington, Kentuky USA 1988)

8. G. Foglianti, S. Alvisi, M. Franchini, E. Todini. J. Water Resour. Plann. Manage., 146(8) (2020).

9. E. Todini. J. of Hydroinformatics. 132, 167 (2011)

10. M.G. Suharev, R.V. Popov. Izvestia RAS. Energetics, 2, 150 (2015) [in Russian]

11. R.V. Popov. In: Proceeding of XIV All-Russian Scientific seminar «Mathematical Models and Methods of the Analysis and Optimal Synthesis of the Developing Pipeline and Hydraulic Systems», 83 (Belokurikha, Altai region, 8-13 September 2014) [in Russian]

12. L.B. Korelstein, E.S. Pashenkova. In: Piping systems of Energetics, 80 (Novosibirsk, Nauka, 2008) [in Russian]

13. L.B. Korelstein, E.S. Pashenkova. In: Piping systems of Energetics. Mathematical modeling and optimization, 103 (Novosibirsk, Nauka, 2010) [in Russian]

14. A.V. Babenko. Oil and Gas Technologies, 2(85), 53 (2013) [in Russian]

15. E.F. Yudovina, E.S. Pashenkova, L.B. Korelstein. In: Piping systems of Energetics. Methodical and applied problems of mathematical simulation, 438 (Novosibirsk, Nauka, 2015) [in Russian]

16. L. Korelshteyn. In: Proceedings of AIChE 2015 Spring Meeting and $11^{\text {th }}$ Global Congress on Process Safety (26-30 April 2015, Austin, TX, USA)

17. L.B. Korelstein. In: Proceeding of XVI All-Russian Scientific seminar «Mathematical Models and Methods of the Analysis and Optimal Synthesis of the Developing Pipeline and Hydraulic Systems», 84 (Irkutsk, 26 June - 02 July 2018, ESI SB RAS) [in Russian]

18. L. Korelstein. E3S Web of Conferences. 102, 01004 (2019)

19. L. Korelstein. E3S Web of Conferences. 102, 01005 (2019)

20. F.R. Gantmaher. The Theory of Matrices. 1 (2012). 2 (2018)

21. P. Azimzadeh. https://arxiv.org/pdf/1701.06951.pdf

22. R.J. Plemmons. Linear Algebra and Its Applications, 18, 175 (1977)

23. C.R. Johnson. Linear Algebra and its Applications, 47, 195 (1982)

24. C.R. Johnson, R.L. Smith. Linear Algebra and its Applications, 435, 5, 953 (2011) 